\title{
Research on Crisis Perception Model of P2P Network Lending Platform
}

\author{
Gang Chen \\ School of Information Management and Engineering \\ Shanghai University of Finance and Economics \\ Shanghai, China \\ gladychen@126.com
}

\begin{abstract}
According to the risk characteristics of the P2P network lending platform, the paper summarizes the influencing factors of the perceived risk comprehensively. It extracts the appropriate P2P network lending platform for the perceived risk dimensions. Material capital variables have a direct impact on perceived risk dimensions. User factors are affected by the user's perspective, and it has a direct impact on perceived risk. Web site features variables have a direct impact on perceived risk dimensions. Social environment impact of this variable on the impact of perceived risk is not significant.
\end{abstract}

Keywords-P2P network lending model; perceived risk; Material capital; User factor; Website features; social environment

\section{INTRODUCTION}

The development of information and communication technology has greatly promoted the development of small loan and the mode of innovation, that is, P2P (Peer-to-Peer) network lending model. P2P network lending model is a kind of way that does not depend on the traditional financial institutions. It is directly on the Internet through trading platform to realize the financial lending business. It is a combination of Internet technology and financial services. So it is a kind of financial services innovation. P2P network lending platform is the P2P network lending services financial services website.

In 2007 the first P2P network lending model platform founded in China. It is pat loan site in Shanghai. From 2007 to 2015 P2P network loan model platform turnover of more than one trillion RMB. P2P network lending platform would become the most important part of Internet banking. It is given the task of financial innovation and expected to ease the financing difficulties of small and medium-sized enterprises. However, by the beginning of the second half of 2015, some P2P network lending companies collapse one after another and bring huge losses to investors. It has caused a very bad social impact and disrupted the stability of the P2P network lending system seriously. It has brought a huge negative impact on the sustained and healthy of development of P2P network lending companies. According to the statistics, at the end of 2015 there are 1263 issues of P2P network lending platform, accounting for the proportion of all platforms up to $32.7 \%$. in China.

If the regulators of the $\mathrm{P} 2 \mathrm{P}$ network lending platform are over regulation then it would be restrain its development. If the regulation is too loose, the $\mathrm{P} 2 \mathrm{P}$ network lending industry would become the migration of opportunism in regulatory policy edge. Therefore, the perceived risk of P2P network lending platform is more important.

According to the risk characteristics of the P2P network lending platform, the paper summarizes the influencing factors of the perceived risk comprehensively. Extract the appropriate P2P network lending platform for the perceived risk dimensions. And construct the research model. This study developed a set of Internet banking products for the perceived risk factors of the measurement scale systematically, the use of a questionnaire for data collection.

Because P2P network lending platform loans using the Internet as a medium of exchange, the risk characteristics not only have borrowed loan risk characteristics, but also have the characteristics of the network, which is a remarkable feature of the P2P network lending platform.

For example, some users want to obtain ultra-high income, they invest Internet banking products. But ultimately cause property damage. At this time, there is the intention to the user to use product of $\mathrm{P} 2 \mathrm{P}$ network lending platform will have anxiety and discomfort. The user perceived risk enhancement.

The Internet as a medium of exchange, network security issues and financial products' risk will increase. The user's perceived risk, this study through the survey data, analysis of the influencing factors of perceived risk can help users find anxiety by the use of Internet banking products. It can also help developers understand of the Internet financial products, perceived risk sources and implement more effective marketing strategy.

\section{P2P NETWORK LENDING PLATFORM PERCEIVED RISK DIMENSIONS}

Risk perception is consumers in buying products to meet the objective risk psychological feelings and subjective knowledge. It is the consumer because of unforeseen purchase the pros and cons of the results and produces a sense of uncertainty.

P2P network by the influence factors of the perceived risk of lending platform, at each stage of the transaction, users will not have responded to all stimuli, but choice of information of 
receiving, processing and understanding. Therefore, the user's perceived level of risk is different and affect the user of the information is perceived risk factors.

This study through the reading of a large number of literature, there are four aspects of a full range of exploring material capital, user factors, website features and social environment. Material capital includes products' yield rate, products' redemption speed, convenience and rapidity of products. User factors include product knowledge, risk attitude. Website features includes convenience of online trading, security of online transactions, authenticity of online information. Social environment includes friend, collective sense and laws.

\section{A. Material capital}

On the P2P network lending platform, due to the impact of internal and external environmental uncertainties, taking into account the serious consequences of the wrong decisions trading process of users would be triggered. Therefore user would have a sense of risk. The products on P2P network lending platform as the research object has its own characteristics such as: product yield rate, products' redemption speed, convenience and rapidity of product etc. It will affect the user's perception of risk.

- Products' yield rate

Products' yield rate is the value of P2P network lending products reflected. If the user uses the P2P network lending product yields fluctuate greatly, the user's perceived risk would increase.

\section{- Products' redemption speed}

The speed of redemption is an important aspect of the impact of investors to invest in financial management. Once the redemption rate slower, investors will consider whether to invest, because this will affects user's next investment. If there has a higher rate of return products in market, investors would have a certain degree of loss. If the products what they have can't be redemption timely. And psychological risk will greatly improve.

\section{- Convenience and rapidity of products}

Since most users on P2P network lending platform would not have more financial knowledge. So if financial products on P2P network lending platform are simpler and more convenient, there would have more user stickiness.

Product characteristic is the objective factor that affects the perceived risk. It is the influence of the product itself to the dimension of user's perceived risk.

\section{B. User factors}

The user is the main transaction. The subjective understanding of users is able to reduce uncertainty, increase the use of results and have a direct impact. User factors includes product knowledge and risk attitude to product.

- Knowledge of product
Users as the main body of the transaction, Product knowledge of users has a direct impact on the perceived risk. Product knowledge can be explained from three factors: familiarity of the product, professional knowledge of the product and the purchase experience of the product. Be familiar with product refers to the user level of understanding of the product. If users know more about products users tend to eliminate the feeling of uncertainty, and it would affect the decision results. The professional knowledge of the product refers to the actual user master product knowledge User's financial experience and Internet experience will have an impact on its use of Internet banking products.

\section{- Risk attitude}

Risk attitude has a direct impact on the user's perception of risk, which reflects the user's tolerance for uncertainty in the whole transaction process. Risk attitude refers to the extent to which users can take in the risk. According to the degree of risk aversion, risk attitude can be divided into three categories: risk aversion type refers to the user to accept the degree of uncertainty of the income is low. Risk loving type refers to the relatively small risk of the transaction processing. Users prefer to accept the risk of greater decision-making. Risk neutral difference and the above two types, the user does not require compensation of risk.

Different risk attitudes will lead users to make different decisions, thereby affecting the user's financial planning.

\section{Website features}

P2P network lending platform is the media to complete all the trading activities on Internet. Website features of P2P network platform for the user's perception of the impact of the product's perceived risk. This article will summarize the factors from three aspects: convenience of online trading, Security of online transaction and authenticity of online information.

\section{- Convenience of online trading}

The convenience of online transactions covering whole process of $\mathrm{P} 2 \mathrm{P}$ network lending platform people use $\mathrm{P} 2 \mathrm{P}$ network lending platform by information seeking process, transaction process and after-sales service, such as web interface design is friendly, website interface design is easy to operate, site after-sales service is perfect etc. The better the convenience of the site, the more satisfaction the user have. Perceived risk will be reduced.

\section{- Security of online transactions}

Security problems of online transactions is the user's most worried about the problem of online transactions. Personal information was leaked. Account password was stolen. Transaction information was intercepted. Web site should prevent security risks. If the web site has less security problems the user would has less anxiety and lower perceived risk.

- Authenticity of online information

Authenticity of online information, including information on the website of the Internet financial products is true, whether the product information on the site to promote the authenticity of the information on the site to comment on 
whether reliable, web site is true, etc.. Website promotion is one of the Internet financial products the most important means of propaganda, disclosure of the information is true, the higher the trust degree of the users of the, use will be more intense, was accomplished using a probabilistic results is greater, namely perceived risk is smaller.

Influence of site characteristics on the perceived risk of Internet financial products belong to the platform, the trading platform security, credit rating affects the user's perceived risk. Therefore, the research to it as one of the influencing factors of perceived risk.

\section{D. social environment}

The user as an individual in the social environment, the perceived risk is likely to be affected by certain aspects of social environment.

\section{- Friend's advises}

Internal communication behavior theory of user groups pointed out that users will use Internet banking product information, use the evaluation and psychological feelings, tell, propagation, pour in the group to other users, in order to obtain other user's understanding, understanding and recognition. Users and friends often have common financial characteristics, and therefore the recommendations of friends, views and evaluation is likely to affect the user's financial behavior.

- Collective sense

According to the theory of rational behavior, we know that the user behavior is directly influenced by social environment, that is to say the thought and evaluation of the user around them can affect their buying behavior. This study suggests that the collective sense of promotion of financial products on the Internet can also affect the user perceived risk of Internet financial products to a certain extent.

- Law of P2P network lending model platform

Mainly refers to the law of relevant rules and regulations of the state or the relevant authority of financial products on the Internet financial characteristics as well as Internet banking product distributors and users in pre transaction relates to the property security and security of personal information, transaction safety. The laws, regulations and policies can eliminate user's concerns and increase the user's wishes. Therefore, this study will be one of the influencing factors of law as a measure of perceived risk.

\section{PERCEIVED RISK DIMENSIONS INFLUENCE DEGREE ANALYSIS}

First, the importance of indicators would be judged by the comparison. We use number $1 \sim 9$ to identified the importance of indicators.

We can get judgment matrix about the importance of indicators.

$\mathrm{M}$ is the judgment matrix. $\mathrm{u}$ is the elements in judgment matrix. $\gamma$ is eigenvalue, $\mathrm{T}$ is a weight vector, $\mathrm{n}$ is product of each line of $\mathrm{M}$. W is $\mathrm{N}$ root mean square of $\mathrm{M}$. CI is checking formulas of consistency. RI is random consistency index.

$$
M=\left[\begin{array}{l}
U_{11}, U_{12}, \ldots . U_{1 n} \\
U_{21}, U_{22}, \ldots . U_{2 n} \\
\ldots \ldots \ldots \ldots \ldots . . . . \\
U_{n 1}, U_{n 2}, \ldots . U_{n m}
\end{array}\right]
$$

$\lambda_{\max } \lambda_{\max }$ is the biggest characteristic root. Weight vector is T. Calculation of Matrix weight is as following.

Quadrature of each line of the matrix $\mathrm{M}$ is:

$$
N_{i}=\prod_{j=1}^{n} M_{i j} \quad(\mathrm{i}=1,2, \ldots \mathrm{n})
$$

$\mathrm{N}$ root mean square of $\mathrm{M}$ is

$$
\bar{W}=\sqrt[n]{M_{i j}} \quad(\mathrm{i}=1,2, \ldots . \mathrm{n})
$$

$$
\text { After standardization } W_{i}=\frac{\overline{W_{i}}}{\sum_{j=1}^{n} \overline{W_{i}}} \quad(\mathrm{i}=1,2, \ldots . . \mathrm{n})
$$

The biggest characteristic root is as following.

$$
C I=\frac{\lambda_{\max } n}{n-1}
$$

$\mathrm{I}, \mathrm{j}$ is $\mathrm{i}$ rows and $\mathrm{j}$ columns.

The consistency check of the judgment matrix is made by the formula.

$$
C I=\frac{\lambda_{\max } n}{n-1}
$$

$\mathrm{N}$ is the order of judge matrix $\mathrm{M}$.

When

$$
C R=\frac{C I}{R I}<0.1 \quad C R=\frac{C I}{R I}<0.1 \quad \text { then }
$$

consistency of the judgment matrix can be considered.

RI value can be found in table 1

TABLE I. RANDOM CONSISTENCY INDEX RI VALUE

\begin{tabular}{|c|c|c|c|c|c|c|c|c|c|c|c|}
\hline $\mathrm{n}$ & 1 & 2 & 3 & 4 & 5 & 6 & 7 & 8 & 9 & 10 & 11 \\
\hline $\mathrm{RI}$ & 0 & 0 & 0.58 & 0.9 & 1.12 & 1.24 & 1.32 & 1.41 & 1.45 & 1.49 & 1.51 \\
\hline
\end{tabular}

Calculated by Matlab software, the characteristic matrix M's the maximum judging value and the corresponding orthogonal unit feature vector

$$
\begin{aligned}
& \lambda_{\max }=4.117 \lambda_{\max }=4.117 \\
& C R<0.1 \omega_{a}=(0.118,0.055,0.565,0.262)^{T}
\end{aligned}
$$




$$
\begin{gathered}
C I_{a}=\frac{\lambda_{\max }-n}{n-1}=0.039 \\
C R_{\alpha}=\frac{C I_{\alpha}}{R I_{\alpha}}=0.044<0.1
\end{gathered}
$$

Consistency test results

$C R<0.1$ so pass.

\section{EMPIRICAL RESEARCH}

This paper uses the method of questionnaire survey to collect the sample data. The questionnaire is divided into two parts: the measurement scale, the user's personal information.

Measure scale is the core part of the questionnaire, the main impact survey respondents use Internet banking products, and what will increase user uncertainty, including risk attitude, product knowledge, economic risk, privacy risks.

User's personal information is the basic information of respondents what were investigated, including gender, age, occupation, educational level, monthly disposable income, whether or not to use too Internet financial products.

The age of this investigation objects locked for 20 years to 40 years old, questionnaire on demographics, gender, monthly disposable income, occupation, age measurement project design. Also in order to make the questionnaire survey, as far as possible, reflect the users use Internet banking products, in the questionnaire, a reverse problem, after the recovery of the questionnaire, the were screened, the unqualified were removed.213 copies were recovered and 110 valid questionnaires were finally obtained through screening.

This study uses partial least squares method (Partial Least Squares, PLS) model parameters. The use of tools is SmartPLS2.0 statistical analysis software.

Reliability analysis was used to test the stability and consistency of the measurement of the amount of the latent variables. Alpha Cronbach's coefficient of each variable is tested and the result is more than 0.7. Therefore, the scale of this study has good internal consistency reliability.

To examine whether the scale used in this study can effectively measure the degree to which it is to be measured. Validity is used to evaluate whether the scale is able to measure the indicators of the latent variables to be measured. In the present study, we used confirmatory factor analysis to test the convergent validity (validity convergent) and discriminant validity (validity discriminate).

Variances Extracted Average, (AVE) is commonly used to test Convergent validity. The standard load factor of the observation items should be more than 0.5 , and the average variance extraction should be more than 0.5.In this paper, the SmartPLS2.0 software was used to test the validity of the scale.
Analysis results show that the average extraction variance of each latent variable is greater than the threshold value of 0.5 .

Discriminant validity is refers to the measurement of different latent variables measurement items of the correlation should be very low. The analysis results show that the average root mean square root of the latent variables is larger than that of the correlation coefficient between the variables and other variables.

\section{CONCLUSION}

Material capital variables have a direct impact on perceived risk dimensions. Specifically, whether the user chooses the financial products, the influence of external risk perception of the size of is secondary. The key is the product itself, if the product yield rate, redemption rate, convenience in line with the user's mind, the user's perception of risk will be significantly reduced. On the contrary, the user will select alternatives for finance and investment.

User factor includes Knowledge of product and risk attitude variables are affected by the user's perspective, and t have a direct impact on perceived risk. If users understand financial knowledge and financial characteristics of financial products on the Internet deeply, then perceived risk is lower. Internet banking products intention of users would be more strongly.

Web site features variables have a direct impact on perceived risk dimensions. Internet financial products are Internet banking a channel of innovative products. Website characteristics on perceived risk would not be ignored.

Social environment impact of this variable on the impact of perceived risk is not significant.

\section{REFERENCES}

[1] Chen Gang, Data center management plan in cloud computing environment. In: 3rd International Conference on Information Management, Innovation Management and Industrial Engineering, ICIII, vol. 4, pp. 393-396, 2010.

[2] Chen Gang, Risk evaluation of business continuity management by using green technology. Communications in Computer and Information Science, 113, pp. 86-92, 2010.

[3] Ellen G, Michal S..Gender Differences in the perceived risk of buying online and the effects of receiving a site recommendation. Journal of Business Research, 57 : 768-775. 2004

[4] Hanjun et al.. Cross-cultural differences in perceived risk of online shopping. Journal of Interactive Advertising, 4(2) : 20-37. 2004

[5] Garbarinoa. E. Strahilevitzb.Gender Differences in the Perceived Risk of Buying Online and the Effects of Receiving a Site Recommendation. Journal of Business Research. PP768-775. .2004

[6] Crespo, A. Herrero,del Bosque, I. Rodriguez,de los Salmones Sanchez, M. M. Garcia.. The influence of perceived risk on Internet shopping behavior: a multidimensional perspective. Journal of Risk Research, Vol. 12, Issue 2, p259-277. 2009

[7] Chen Gang, Decision-making model of business continuity management. Lecture Notes in Electrical Engineering, 140, pp. 285-289, 2012.

[8] Mitchell.VW..ReeoneePtualizingeonsumerstoreimageProeessingusingPe reeivedrisk.Joumalofbusinessresearch,vol.54,IssueZ,PP.167-172. 2001 